\title{
ETHNIC SEGREGATION IN TEL-AVIV - JAFFA'
}

\author{
Izhak Schnell \& Yoav Benjamini \\ Tel Aviv University, Israel \\ e-mail: schnell@post.tau.ac.il
}

\begin{abstract}
In the article analysis of the segregation of 1000 representatives of eight important ethnic groups in Tel-Aviv - Jaffa is represented. The comparison of results was made on the basis of index of dissimilation. Each ethnical group is analysed with regard to its spatial distribution, a sample of each group being analysed on the basis of the index of dissimilation as well as spatial and interactive segregation.
\end{abstract}

Key words: Tel-Aviv - Jaffa, segregation, ethnical groups, dissimilation, social structure, spatial isolation.

\section{INTRODUCTION}

Until the nineties most of the literature on spatial segregation focussed on the discovery of spatial forms of segregation in Cartesian space, assuming that the city is constituted of a mosaic of homogeneous social areas which contain their inhabitants life. In addition, schoolars used to analyse the forces that shape these segregated forms separately based either on positivist, behavioural, or structural approaches (Jackson \& Smith, 1984). In accordance, spatial segregation indices focus on measuring the uneven distribution of the groups in residential spaces and less on their isolation from inter-ethnic interactions in everyday life spaces. In general a set of five complementary indices that describe social groups' distribution and location in urban space has been institutionalized in segregation researches (Massey and Denton, 1988). New attempts to improve measurements focus on calculating the number of residents who would need to relocate and the degree of effort needed to enable an even distribution in residential space among these groups (Morgan, 1983; Morrill, 1991; Waldorf, 1993, Wong, 1998).

In former works we have suggested that under globalization there is a need to supplement current segregation studies with an index that emphasises individual agents' ex-

\footnotetext{
${ }^{1}$ We thank the GIF - German Israeli Foundation and the Ministry of Science in Israel for financing the research projects on which the paper relies.

The paper is presented in Lublijana, 17-23.8.2003
} 
periences of isolation from or exposure to everyday life spaces of other groups, an argument that has been supported by Benenson and Omer (2002). Unlike Benenson and Omer, we have also argued that segregation should represent not only the agents' location in respect to the identities of their neighbours in residential space, but also in respect to the spaces in which they practice their everyday life, mingle with meaningful others and develop their socio-spatial networks (Schnell and Benjamini, 2001; Schnell, 2002). This aspect of the model is based on the assumption that the associations between locally based neighbourhoods and everyday life activity spaces, social networks and sources of identity formation, are highly eroded in late modern ages, being opened to global horizons at least for some social groups (Bauman, 1995) At a second stage we have suggested aggregating the results to social groups, evaluating to what extent they share common orientation toward socio-spatial segregation and mapping their distribution in space (Schnell and Benjamini, 1999; 2001; Schnell, 2002). Our model differs from conventional models mainly in two aspects: First, we suggest treating segregation as a human behavior that should be studied for individuals prior to any attempt for aggregation. As an individually based index, the key question is what are the probabilities and the choices of persons to encounter others from their own groups or alternative groups while they perform their daily routines in their everyday life spaces. Second, we suggest studying segregation in respect to agents' everyday life spaces rather than in respect to their neighbors in residential space. The justification for it requires a lengthy discussion, which is presented in our former papers.

Our goal in this paper is to analyze the patterns of segregation of 1000 individual members of eight significant ethnic groups in Tel-Aviv - Jaffa and to compare these results to the one calculated by the traditional dissimilarity index. We describe the spatial distribution of members of each ethnic group in the city, we analyze their patterns of segregation based on conventional dissimilarity index and we analyze the territorial and interactive segregation of the protagonists based on our indices. This enables us to answer the following questions: First, to what extent may we observe significant differences in segregation among members of the same ethnic group? Second, to what extent can we observe differences between territorial and interactive degrees of segregation in individuals' experiences, and to what extent are these results explained by homogeneity vs. Heterogeneity of the protagonists' neighborhoods? Third, to what extent can we observe significant inter-ethnic variances in segregation levels and patterns? We argue that the results justify the replacement of the Chicago model, which suggest to view social areas as a continuous mosaic of homogeneous containers to a multi-layered model of relatively open areas which may overlap with layers of other groups social areas, constituting heterogeneous residential spaces even among socially segregated groups.

We develop our argument in four stages. First, we describe the social structure of Tel Aviv residents in order to identify meaningful social groups. Second, we argue that ethnicity in Tel-Aviv-Jaffa matters. Third, we describe the distribution of our protagonists in social space. Forth, we analyze our territorial and interactive segregation for the 1000 valid protagonists as a base for the test of our research questions. 


\section{SOCIAL SPACE IN TEL-AVIV-JAFFA}

It is increasingly recognized that the different ethnic groups of immigrants that were supposed to integrate into a homogeneous society in the Zionist process of nation building are, in fact, re-fragmenting into different sub-cultures with different Israeli sub-identities. These groups are divided along national, ethnic, religious and ideological cleavages; which derive from ethnic roots, wide-ranging cultural differences or fierce ideological public debate (Peled and Shafir, 1993; Lisak, 2000; Ben-Rafael, 2000; Ya'ar, 2001). The relative importance of each cleavage depends on the factors that shape public discourse, whether the Israeli-Palestinian conflict, religious-secular conflicts or ethnic ones. It seems that three forces compete for the establishment of a new hegemony. One, the Neo-Zionist alliance promotes a particularistic Jewish communal solidarity that includes all Jewish groups regardless of their ethnic origin and firmly excludes non-Jews. They seek to extend the territorial frontiers into the Biblical territories that define national identity (Schnell, 2002; Newman, 2001). The other is the late- and post-Zionist alliance that upholds the supremacy of a civil consumerist society favouring neoliberal values. This society seeks to be part of a globalizing world, and at home is willing to recognize marginal groups separate identities under its hegemoney, including non-Jews. In accordance, they preach also to establish a Palestinian state in the occupied territories (Schnell, 2001; 2003; Newman, 2001). The third is constituted of different resisting groups from formerly marginalized ethnic groups who were forced out of the melting pot during the sixties and the seventies. Their resistance to the socio-economic consequences of globalization further fuels their tendency to fragment Israeli society into ethnic sectors. It is argued that the three tendencies co-exist in the current historical situation (Peled, 1992; Ram, 1999).

The threefold model in which there is wide social agreement among Jews about the exclusion of non-Jewish identities, and the fierce marginalization of immigrants from Ethiopia and the ultra-Orthodox as well as partial marginalization of the immigrants from the former Soviet Union, the Religious Mizrahi Jews, has been validated in Tel-Aviv - Jaffa (Schnell, Hop and Harpaz, 2004). The processes of exclusion act along three cleavages: the national, in which all Jewish sectors share the exclusion of non-Jewish groups; the religious, in which the secular groups marginalize the different religious groups, while at least the National Religious group tends to include most of the Jewish sub-identities; and the ethnic cleavage, in which the secular Ashkenazi Jews and, to large extent, also the secular Mizrahi Jews represent the legitimate Israeli identity on the one hand and the marginalization of Jewish resistance groups on the other.

Based on interviews on attitudes towards inter-group social distance we detected three basic sets of attitudes: The civil worldview that rejects any form of exclusion or prioritization based on communal belonging is adopted by only 20 percent of the city residents. They are recruited from all secular segments of Israeli society. In contrast 60 percent of the city residents represent a nationalist attitude which exclude none-Jews from the national collective, the vast majority of them (54 percent of the total sample) marginalizing at least some of the Jewish groups either on the ethnic dimension or the religious dimension. The more 
than half of the sample who emphasize their sectarian identities are coming from most sectors of society but more from the secular upper-middle class citizens who tend to reject the legitimacy of Jewish resistance groups. In the same token, those who belong to the two hegemonies groups tend to view themselves as none cohesive groups. Members of resistance groups are perceived to be highly internally cohesive communities who tend to identify closely with their sectarian groups, while presenting relatively long distance to other groups adopting, by thus, also sectarian set of attitudes. The high correlation between the degree of a group's exclusion from the Israeli legitimate identity and its internal cohesion, supports our argument that sectarian identities may be associated with the adoption of resistance strategies (Schnell, Hopp and Harpaz 2004).

The ethnic structure of the city population remains very stable across the city different sub-quarters. Only in the Arab-dominated quarter of Jaffa, does the basic pattern change. There, the Arabs perceive that they dominate the neighborhood. Nevertheless, one can find significant differences among sub-quarters across the city in accord with local agendas. In this context it may be concluded that ethnicity matters in Tel-Aviv-Jaffa. In accordance it may be expected that while the secular Ashkenazi and Mizrachi groups are expected to avoid any form of segregation, while the resistance groups are expected to present a more segregated pattern of behavior with the more cohesive groups presenting stronger levels of segregation.

\section{MEASURING SOCIO-SPATIAL SEGREGATION}

\section{General}

The most basic common measurement of segregation is suggested by Boal for international comparison (Boal, 1987). It is calculated as the proportion of members of a group in segregated areas in respect to their total population, minus the proportion of members of alternative groups in the segregated area in respect to the total number of the member of the other groups in the city as a whole. We have used this Dissimilarity Index as a comparison to our new index. We believe that while the D.I. measures groups' distribution in residential space relative to the distribution of alternative groups, our index measures person isolation or integration in society at large in performing ones daily life and developing ones social networks.

In constituting our indices the basic unit of analysis is an agent who is located in a home site. We measure the agent's level of segregation as a proportion between similar and nonesimilar others in respect to everyday life activity spaces. Any activity is measured along two axes. An interactive dimension designated by the social identity of meaningful others is measured along three major spheres of daily activities: meetings with mates at work, meetings with friends and telecommunication. A territorial dimension designated by three concentric territorial bases is measured spatially: close vicinity; neighborhood and beyond. The impact of each of the daily activity spheres and the territorial bases on the total rates of isolation for every individual is weighted according to the proportion of waking daily hours 
spent in each interactive sphere and territorial base. This is further modified by the relative salience that the agent assigns to each interactive sphere and territorial base, respectively. An agent's rate of socio-spatial isolation is, then, calculated as the sum of weighted average of isolation or exposure in relation to the social identities of meaningful others in the three interactive spheres and the weighted average of potential encounters with members of other groups in three territorial bases.

\section{The proportions}

The initial building stones of the socio-spatial isolation indices are the proportions between the number of members of the studied group and alternative groups for each of the territorial and interactive aspects of the indices. Thus, for the territory $r$, (for example the close vicinity) with $n_{r}(i)$ being the number of the group's members who live in territory $r$ where agent $i$ lives, and $N_{r}(i)$ being the total number living in that same territory the proportion is

$$
S_{r}(i)=\frac{n_{r}(i)}{N_{r}(i)}
$$

In the same way, for the sphere of interactions $q$, (for examples with friends) with $n_{q}(i)$ being the number of those being encountered by agent $i$ who belong to the same identity group of agent $i$ and $N_{q}(i)$ being the total number of others being encountered by the agent the proportion is

$$
S_{q}(i)=\frac{n_{q}(i)}{N_{q}(i)}
$$

\section{The weights}

Having presented the set of proportions, let us turn to the essence of the weighting process, which includes the three aforementioned interactive spheres and the three territorial bases. The weighting process is essential to the characterization of the overall isolation assessment and may involve two types of weights: time related weights and salience related weights. One set of time weights measures the proportion of time that agents spend in each of their territorial bases for the territorial isolation index. A second set of time weights measures the proportion of time that agents spend in each of their daily activities for the interactive isolation index. Similarly, two other sets of weights express the relative salience they assign to each of these spatial and social settings. The information leading to the weights can be based on actual observations, on registered self-reporting (diaries) or as we suggest here, on respondents answers to a questionnaire.

If $T_{r}(i)$ is the time spent at home territory $r$, and $V_{r}(i)$ is its perceived salience, we form their product $W_{r}^{*}(i)=T_{r}(i) V_{r}(i)$, and normalize by the sum of these weights over all territorial bases, 
(3) $W_{r}(i)=W_{r}^{*}(i), \Sigma_{r} W_{r}^{*}(i)$

Similarly, if $T_{q}(i)$ is the time spent at activity q, and $V_{q}(i)$ is its perceived salience, we form their product $W^{*}{ }_{q}(i)=T_{q}(i) V_{q}(i)$, and normalize by the sum of these weights over all activity spheres,

$$
\text { (4) } W_{q}(i)=W *_{q}(i) / \Sigma W{ }_{\mathrm{q}}(i)
$$

The results are two sets of weights, each of them sums to 1 . They enable to construct the indices as the weighted averages of three activity spheres, on the one hand, and three territorial bases, on the other.

\section{Combining proportions with weights}

Given a set of weights $\mathrm{W}_{\mathrm{r}}(i)$ which sum to 1 , and which reflects the relative weight of the territorial dimension of the everyday life of agents, we could have combined them most simply by defining

$$
\text { and } \begin{aligned}
& \text { (5) } S P(i)=\Sigma_{r} W_{r}(i) S_{r}(i) \\
& \text { (6) } S O(i)=\Sigma_{q} W_{q}(i) S_{q}(i)
\end{aligned}
$$

But averaging the raw proportions, as in the first scheme, is over-simplified. Instead we propose to do the averaging on a logistic scale: re-expressing each proportion $\mathrm{p}$ by the logistic scale: $s(p)=\log (p /(1-p))$, averaging them using the weights to get $\mathrm{SP}^{*}$ and $\mathrm{SO}^{*}$.

The use of logistic transformations for analysing proportions is not a mere technicality, nor is it novel. That factors contribute linearly to the explanation of observed probabilities when expressed on the logistic scale is one of the reasons that make logistic regression so useful in behavioural studies. In the context of this study, the use of the logistic transformation reflects our conviction that an individual's experience of isolation is not linear in proportion.

Some technical details are in place before we turn to the detailed formulation of the indices. The logistically transformed proportion can be expressed as:

$$
\text { 7) } \log \left[\frac{n_{r}(i) / N_{r}(i)}{1-n_{r}(i) / N_{r}(i)}\right]=\log \left[\frac{n_{r}(i)}{N_{r}(i)-n_{r}(i)}\right]
$$

In practice we add a value of third to each of the counts. Statistically, this sets the transformed values at approximately their expected values for a sample from the logistic distribution. Technically, this also enables the use of the logistic transformation when $n_{r}=N_{r}$ or 
when $n_{r}=0$, thus causing it to perform closer to these two extremes (Tukey 1977). We, therefore, define the close vicinity logistically transformed proportion as

$$
\text { 8) } \quad \mathrm{S} *_{\mathrm{r}}(i)=\log \left[\frac{n_{r}(i)+1 / 3}{N_{r}(i)-n_{r}(i)+1 / 3}\right]
$$

Then, we define the weighted averages

and

$$
\text { 9) } \quad S P^{*}(i)=\Sigma W_{r}(i) S_{r}{ }_{r}(i)
$$

$$
S O^{*}(i)=\Sigma W_{q}(i) S_{q}^{*}(i) .
$$

We calculate also residential homogeneity as the proportion between similar and different neighbors of the protagonist in ones residential vicinity and neighborhood.

$$
\text { 11) } \quad \mathrm{S}_{\text {vicinity/neighborhood }}(i)=\log \left[\frac{n_{r}(i)+1 / 3}{N_{r}(i)-n_{r}(i)+1 / 3}\right]
$$

In conclusion, socio-spatial segregation is calculated as an agent's weighted average rates of isolation, re-transformed from logistic scales in two sets of interactive and territorial contexts within an agent's everyday life space. The agent weights reflect the relative weight of each of these interactive and territorial dimensions both in terms of time spent and perceived importance for their social life. Each of the two complementary indices (SP and SO) may range between the values of 0 and 1 indicating extreme exposure to members of other groups and extreme isolation from members of other groups respectively. The indices are open to the consideration of alternative interactive or territorial categories if they are relevant to the analysis of any particular group's constitution of everyday life practices. However, the adoption of this formulation as a standard structure may enable to make the indices more amenable to comparative studies.

\section{The Samples}

The current study is based on questionnaires in which the protagonists were asked to evaluate their time budgets and their attitudes toward the relative importance of the different interactive and territorial spheres for their social life. We chose the 1600 protagonists in two different samples. First, 960 protagonists were chosen as part of a city sample which includes representatives of 1.3 percent of the city households. We chose in each sub-quarter the proper share of the population and we picked a random sample in each sub-quarter. The sample represent the city population, including all ethnic groups, except for the migrant workers who failed to answer telephone interviews. Second we chose three target ethnic groups who tend to develop different degrees of resistance identities: Immigrants from 
Buchara; Migrant workers and Israeli Arabs or Palestinians. Each sample includes 200 protagonists from their ethnic enclaves with the migrant workers subdivided into 120 Africans and 80 South Americans. A migrant worker and a research assistant using the snowball method personally interviewed the migrant workers. The two other groups were randomly chosen by the telephone interview. Out of that sample we were able to produce 1000 results with the failing cases randomly distributed in space and among all social groups.

\section{Groups' spatial distributions}

The distribution of ethnic groups according to the sample is presented in table 1. The table shows that the largest group is constituted of Israelis. Israelis are those who do not assign themselves any sub-identity either because they were born into ethnically mixed marriages or they are at least three generations in Israel and they chose not to assign their origin any significance. This number is higher than official municipal statistics because it includes also those who officially would have been classified into any ethnic group despite the fact that they refused to be classified in our sample (Tel Aviv Statistical Yearbook, 2000). The second and the third groups are the Ashkenazim and Mizrahim who are slightly smaller in size than the official statistics, and at the end are the minority groups of the Arabs and the Migrant workers. In our current analysis we decided to relate to subgroups in each category, dividing the European Russian immigrants from the Ashkenazim and the highly cohesive Bucharian community from the Mizrahim. We divided also the migrant workers into the African and the South American communities. Only the Arabs were not divided into sub-groups because only few Christians fell into the sample.

Table 1: The sample by social group

\begin{tabular}{|l|l|c|}
\hline No. & The Group & Percent \\
\hline 1 & Israelis & 39 \\
\hline 2 & Ashkenazim & 17 \\
\hline 3 & Mizrahim & 13 \\
\hline 4 & Russian Immigrants & 10 \\
\hline 5 & Bucharian Jews & 7 \\
\hline 6 & Arabs & 7 \\
\hline 7 & Migrant workers & 7 \\
\hline 6 & Total & 100 \\
\hline
\end{tabular}

Our first argument is that ethnic categories in Tel Aviv, as a globalizing city, live in highly heterogeneous residential spaces in almost all city areas. This means that the argument of the Chicago school, which claim to define homogeneous social areas do not apply to the case of Tel-Aviv-Jaffa. An analysis of the homogeneity of the protagonists close vicinities reveals that only 13 percent of them live in homogeneous vicinities with 30 more percent living in mixed vicinities in which about half of their neighbors are similar to them and 57 percent live in vicinities inhabited mainly by people who belong to different ethnic catego- 
ries than their own ones. Even those who live in homogeneous vicinities are dispersed through out the city in mixed neighborhoods, in a way that not even one neighborhood seems to maintain ethnically homogeneous area (Figure 1). This conclusion raises the question whether ethnic groups are evenly distributed in space or tend to concentrate in certain areas of the city. Tables 2 and 3 shed some more light on this matter. From table 2 we learn that Arabs, Bucharian Jews and Migrant workers tend to concentrate in certain areas of the city. More than eighty percent of the Arabs are concentrated in Jaffa while more than sixty percent of the migrant workers and the Bucharian Jews are concentrated in the southern quarter of the city. The Ashkenazim and the Mizrahim present lower tendencies to concentrate in the urban space with the Ashkenazim tending to concentrate in the Old North and the Mizrahim in the South Eastern and the Central quarters.

Figure 1: Residential segregation in close vicinity

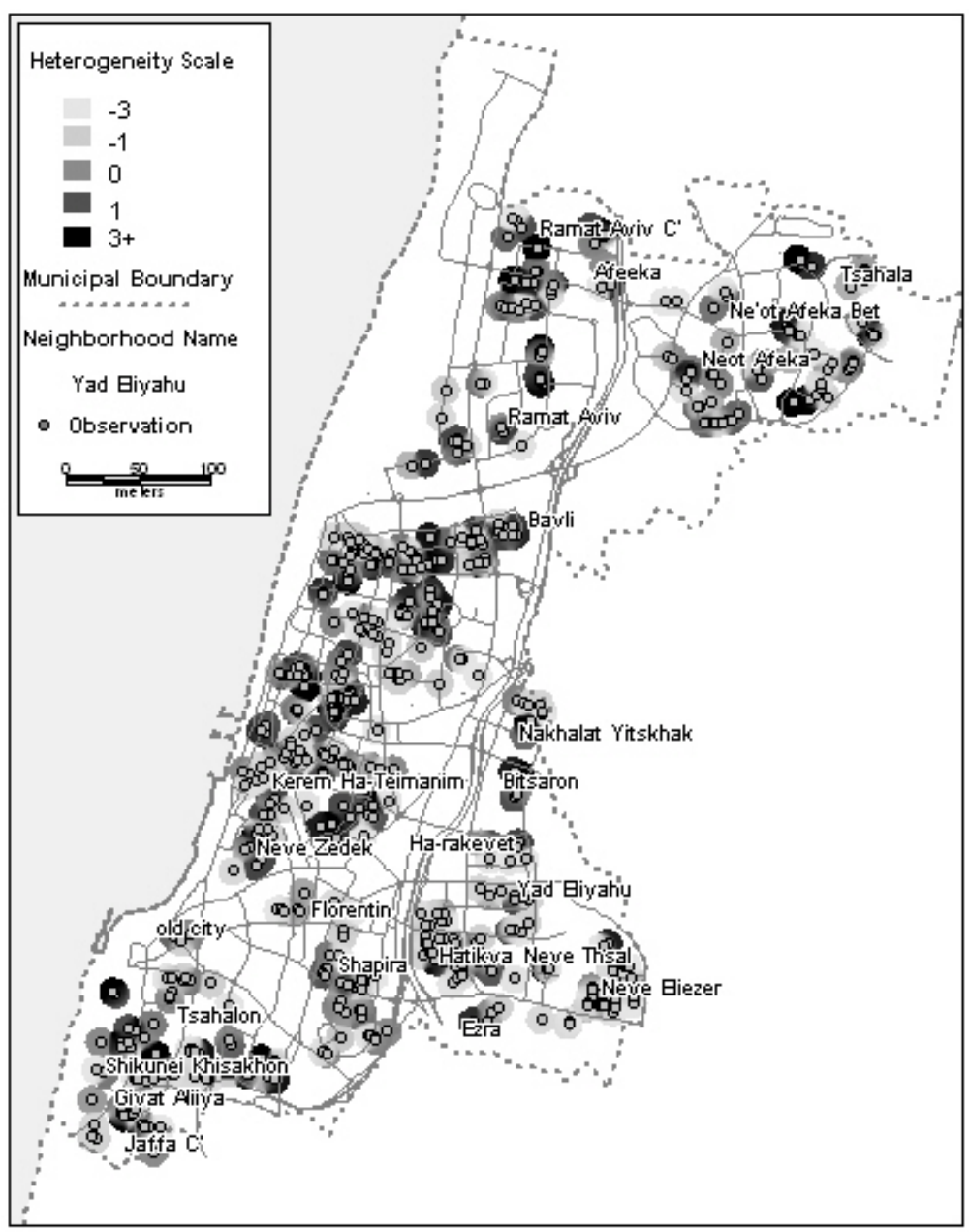


Table 2: Percent of members of ethnic group in area out of total members of the group in the city

\begin{tabular}{|l|r|r|r|r|r|r|r|}
\hline & Israelis & Ashkenazim & Mizrahim & Russians & Bucharians & Arabs & Migrants \\
\hline Jaffa & 14 & 13 & 16 & 23 & 10 & 83 & 5 \\
\hline South & 6 & 3 & 7 & 7 & 60 & 4 & 65 \\
\hline South East & 21 & 3 & 31 & 23 & 20 & 6 & 15 \\
\hline Center & 23 & 18 & 20 & 8 & 10 & 5 & 7 \\
\hline Old North & 18 & 41 & 8 & 21 & 0 & 2 & 4 \\
\hline North & 11 & 9 & 9 & 8 & 0 & 0 & 2 \\
\hline North East & 7 & 13 & 9 & 10 & 0 & 0 & 2 \\
\hline Total & 100 & 100 & 100 & 100 & 100 & 100 & 100 \\
\hline
\end{tabular}

Despite the uneven distribution of the different groups in the urban space none of them tend to create close ghettos in any of the areas of the city (table 3). None of the ethnic groups form a majority in any of the city quarters. Only the Israelis, who refuse to identify with any of the ethnic groups, dominate the city center, which became the stronghold of young urbanite residents (Schnell and Graicer, 1994). Most groups constitute not more than one third of the population in areas they tend to concentrate. Even marginalized minorities like Arabs and Migrant Workers are less than 40 percent of the populations in Jaffa and the South. This means that most Arabs and Migrant workers live in quarters that are highly mixed with different ethnic groups. More detailed maps show that this conclusion is rele-vant even for the smallest social areas of the closed vicinity presented in figure 1. Even the Arabs and the African migrant workers who tend to concentrate in certain areas of the southern part of the city and tend to inhabit between one to two thirds of the protagonists immediate neighbors, the probability of almost all persons to meet members of other groups while reaching to their close vicinities remain higher than 0.35 .

Table 3: Percent of Members of Ethnic group in Area out of total members of the Area

\begin{tabular}{|l|c|c|c|c|c|c|c|}
\hline & Israelis & Ashkenazim & Mizrahim & Russians & Bucharians & Arabs & Migrants \\
\hline Jaffa & 29 & 10 & 13 & 13 & 3 & 30 & 2 \\
\hline South & 15 & 2 & 7 & 4 & 32 & 3 & 37 \\
\hline South East & 41 & 9 & 25 & 10 & 7 & 3 & 5 \\
\hline Center & 62 & 17 & 7 & 5 & 2 & 4 & 3 \\
\hline Old North & 40 & 39 & 7 & 12 & 0 & 1 & 1 \\
\hline North & 53 & 20 & 18 & 9 & 0 & 0 & 0 \\
\hline North East & 42 & 29 & 10 & 16 & 0 & 0 & 0 \\
\hline Total & 39 & 17 & 13 & 10 & 7 & 7 & 7 \\
\hline
\end{tabular}

Measuring the ethnic groups socio-spatial segregation by the simplest dissimilarity index, suggested by Boal (1987) for units equivalent to statistical areas, show that the three minority groups of the Arabs, Migrant Workers and Bucharian Jews are unevenly distributed in space while the rest tend more to an even distribution including the migrants from Russia who live in Israel less than 12 years (Table 4). The question arises whether those who are 
expected to be more segregated according to the dissimilarity indices tend also to perform their daily life in segregated territories and to develop segregated social networks?

Table 4: Ethnic groups 'Dissimilarity Indices

\begin{tabular}{|l|c|}
\hline Ethnic group & D.I. \\
\hline Arabs & 69 \\
\hline Migrant Workers & 56 \\
\hline Bucharian Jews & 51 \\
\hline Russian Immigrants & 26 \\
\hline Mizrahim & 18 \\
\hline Ashkenazim & 29 \\
\hline Israelis & 25 \\
\hline
\end{tabular}

\section{INDIVIDUALS AND GROUPS TENDENCIES FOR SOCIO- SPATIAL ISOLATION}

Within the heterogeneous city people tend to manage their everyday life in none segregated spaces as shown by the territorial segregation index. Two third of the protagonists perform their daily life in mixed territories in which members of their own group are about half of the population of these territories' presenting, by thus, some tendency to prefer areas dominated by their own groups but still within heterogeneous areas. Only four percent of the protagonists tend to perform their everyday life in territories that isolate them from members of alternative ethnic groups (Table 5 and Figure 2). From the forty segregated individuals more than half are members of the Arab and Bucharian groups but even they are highly distributed in space and they are the minority among their groups' members. Most of them are women who due to traditional lifestyle isolate themselves in kinship milieus. The main reason for the further desegregation of activity spaces relative to the desegregation of residential space, is the fact that most agents tend to distribute most of their activities outside their neighborhoods and through out the metropolitan area (Schnell and Benjamini, 2001). This means that almost all respondents are performing their daily life across the metropolitan areas with only few scattered individuals isolating themselves within local ethnic spaces.

Unlike the desegregated activity spaces about one third of the protagonists develop for themselves segregated social networks as shown by the interactive segregation index (Table 5 and figure 3). Another group of 45 percent tend to interact with ethnically mixed milieus giving some preference to interactions with their own group and the rest are fully integrated in the larger society, highly exposing themselves to members of alternative ethnic groups (21 percent of the sample).

The most striking result is the fact that while almost all protagonists live in desegregated vicinities and perform their daily life in desegregated spaces about one third of them are 
closing themselves to ethnically segregated social networks. Furthermore, the segregated individuals are widely spread around the city and they are not concentrated in spatial niches or enclaves. This means that while Tel-Aviv - Jaffa is characterized by ethnically heterogeneous areas in residential space and by inhabitants that perform their everyday life in heterogeneous territories reaching out to large parts of the metropolitan area, many of them develop ethnically segregated spatial layers of social networks (table 5). These layers remain isolated from each other for one third of the protagonists and partly open to inter-layers interaction for additional 45 percent of the protagonists who prefer intra-ethnic social networks but maintain also significant interactions with members of alternative ethnic groups (Table 5).

Figure 2: Territorial segregation

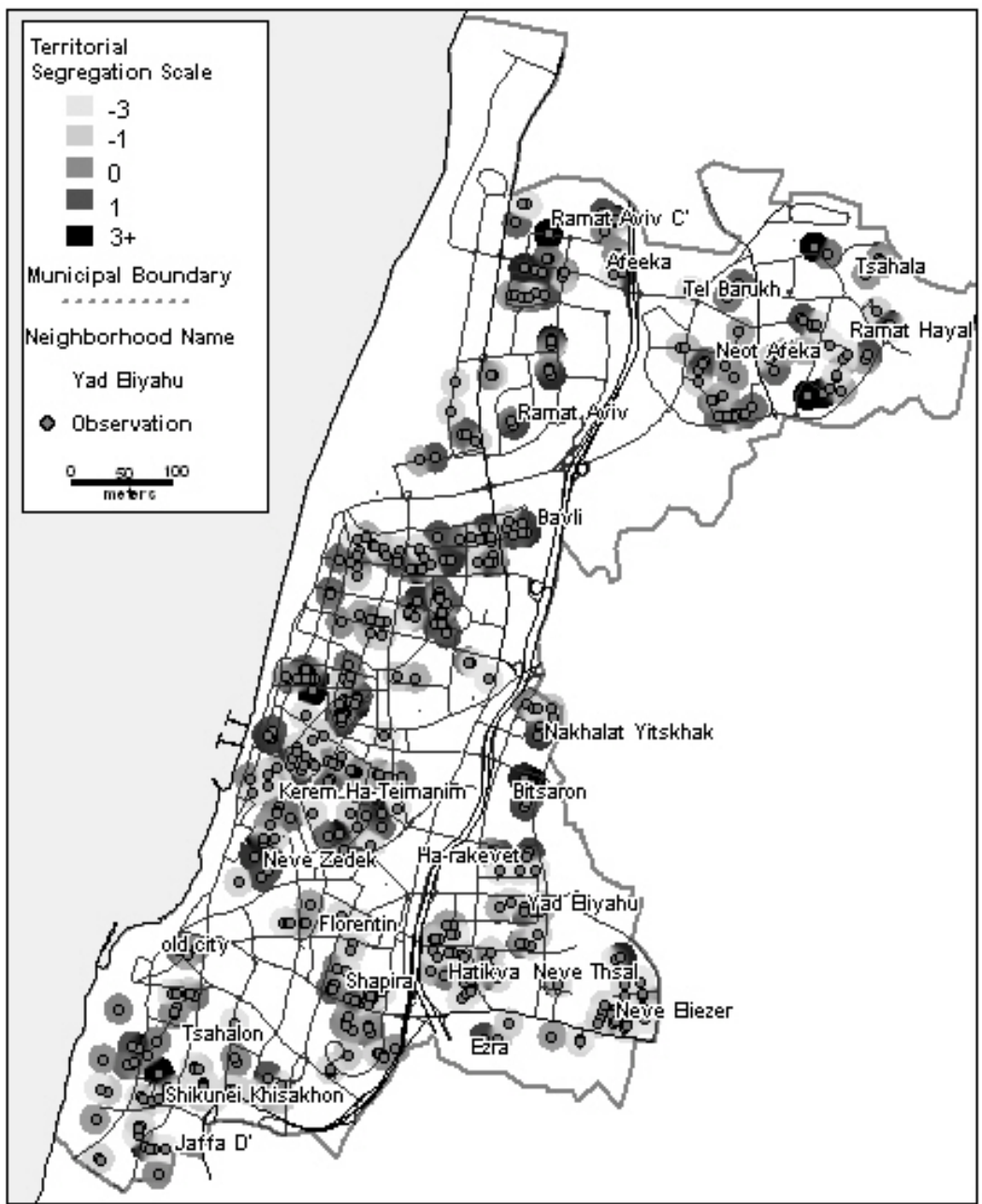


Figure 3: Interactive segregation

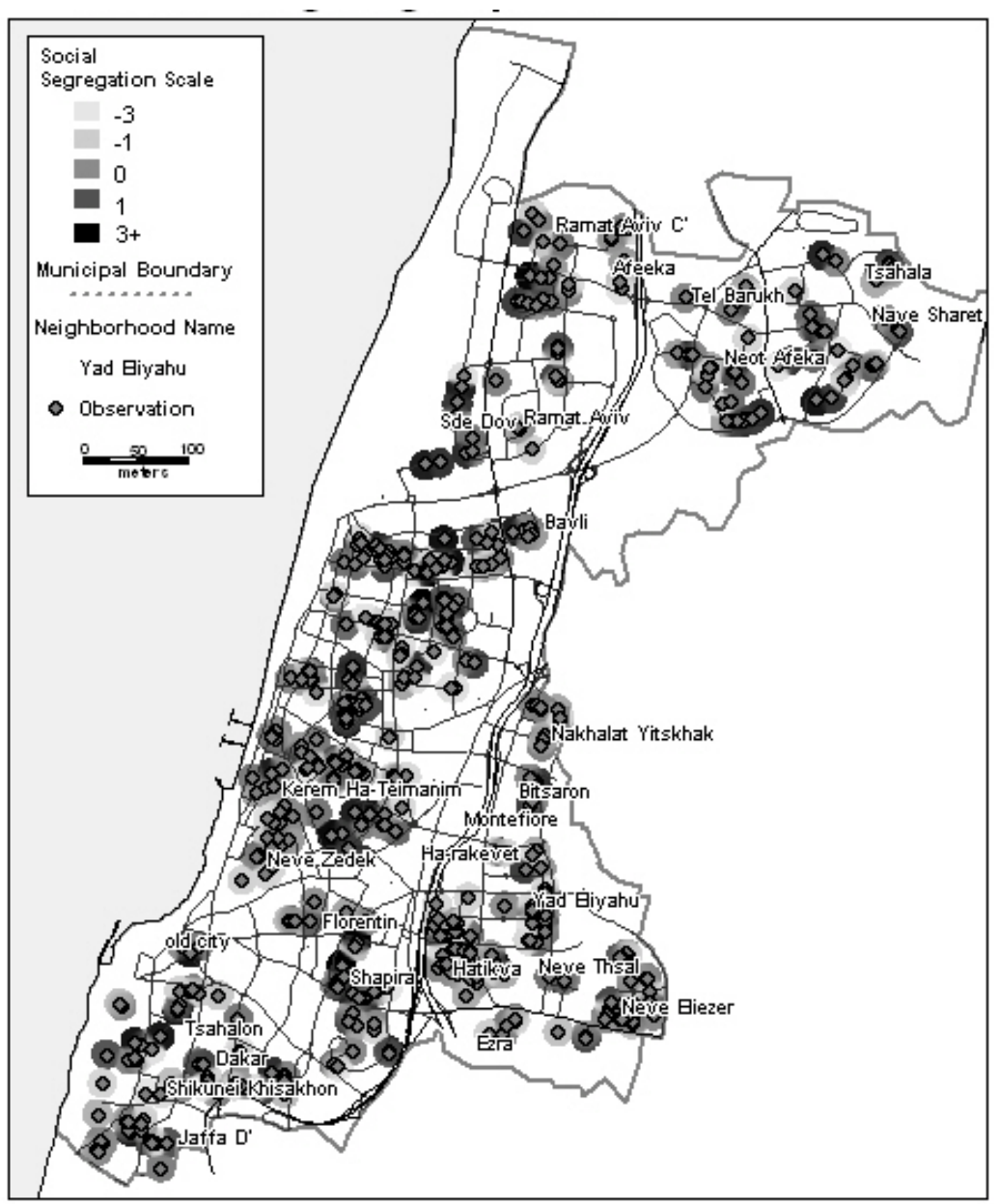

Table 5: Cross-tabulation of interactive and territorial segregation (\%)

\begin{tabular}{|l|c|c|c|c|}
\hline $\begin{array}{c}\text { Interactive } \\
\text { Terrirorial }\end{array}$ & Exposure & Preference & Isolation & Total \\
\hline Exposure & 7 & 16 & 10 & 33 \\
\hline Preference & 13 & 27 & 23 & 63 \\
\hline Isolation & 1 & 2 & 1 & 4 \\
\hline Total & 21 & 45 & 34 & 100 \\
\hline
\end{tabular}

Significant variations in the distribution of segregation values among different social groups may be calculated. Table 6 shows the relatively low degrees of isolation of all groups with the Israeli Arabs, Bucharian immigrants and African migrant workers presenting a 
small group of territorially segregated individuals. The table stresses also the tendency of about two third of the Israeli Arabs and the African migrant workers to segregate in the interactive dimension. It is interesting that about one third of the veteran Ashkenazim also tend to segregate in the interactive dimension as well as about one quarter of the Russian immigrants and Israelis who refuse to subdivide themselves into any ethnic origin.

Table 6: Percent segregated, mixed and exposed by ethnic group

\begin{tabular}{|l|r|r|r|r|r|r|r|r|r|r|}
\hline \multirow{2}{*}{ Ethnic Groups } & \multicolumn{9}{|c|}{ Percent in situation of } & \multicolumn{3}{|c|}{ General distribution } \\
\cline { 2 - 14 } & \multicolumn{2}{|c|}{ Isolation } & \multicolumn{1}{|c|}{ Mixture } & \multicolumn{2}{|c|}{ Exposure } & \multicolumn{2}{|c|}{ Mean } & \multicolumn{2}{|c|}{ S.D. } \\
\hline Ist. & Ter. & Int. & Ter. & Int. & Ter. & Int. & Ter. & Int. & Ter. \\
\hline Veteran Ashkenazim & 25 & 1 & 48 & 97 & 27 & 2 & 0.0 & 0.5 & 1.5 & 0.5 \\
\hline Veteran Mizrahim & 13 & 0 & 44 & 31 & 23 & 69 & 0.2 & -1.2 & 1.7 & 0.6 \\
\hline Russian Immigrants & 27 & 0 & 53 & 11 & 20 & 89 & 0.2 & -1.9 & 1.4 & 0.5 \\
\hline Bucharian Immigrants & 16 & 15 & 31 & 37 & 54 & 48 & -2.0 & -1.0 & 1.1 & 1.0 \\
\hline Israeli Arabs & 62 & 28 & 46 & 33 & 5 & 26 & 0.6 & 0.0 & 2.2 & 1.7 \\
\hline African Migrant Workers & 66 & 11 & 25 & 32 & 9 & 57 & 1.2 & -0.2 & 1.0 & 0.9 \\
\hline S. Am. Migrant Workers & 18 & 0 & 51 & 12 & 30 & 88 & -0.3 & -3.0 & 1.1 & 0.7 \\
\hline Total (Average) & 34 & 4 & 45 & 63 & 21 & 33 & 0.0 & 0.5 & 1.7 & 0.6 \\
\hline
\end{tabular}

Int.$=$ Interactive segregation, Ter.$=$ Territorial segregation

The results so far hints at the fact that residential heterogeneity, territorial and interactive segregation are only loosely correlated in Tel-Aviv-Jaffa. Regression analysis among the three variables reveals that individual's tendency to concentrate into ethnically homogeneous vicinities explain only 7-8 percent of the variability in either territorial or interactive segregation. This means that residential concentration in what is considered by traditional models, as residential segregation only marginally explains residents' spatial behavior in performing everyday life. Both those who live in homogeneous and heterogeneous neighborhoods tend to perform their daily life in none segregated spaces. The relative weight (calculated as an index of relative time spent in spaces and contribution to social life) of the metropolitan area beyond the home neighborhood for the average protagonist reaches $0.74_{11.00}$ with the Arabs and the African migrant workers as the two only exceptions. The Arabs and the African Migrant workers tend to assign high weights to their close vicinities $0.33_{/ 1.00}$ relative to average of $0.07_{/ 1.00}$. African tend to avoid spatial mobility due to their fear of the police as none registered migrants while among the Arabs women tendency to close themselves to their home vicinities explain the high percentage of segregated protagonists. At the same time residential concentration in homogeneous vicinities only 
marginally explain interactive segregation, which is also unexplainable by territorial segregation. It seems that even those who constitute their social networks mainly with others from their ethnic category, recruit their mates from wide spatial horizons in their everyday life spaces, and not necessarily from their neighbors constituting by thus a partly segregated networks space isolated from alternative groups' networks spaces that may be constituted on the same coordinates.

\section{CONCLUSION}

Residential, territorial and interactive segregation indices are varying among different residences of the city even when they belong to the same ethnic groups. Furthermore, residential segregation does not explain residents' tendency to isolate themselves in closed everyday life activity spaces and in mono-ethnic social networks. This raises a question what can be learnt from dissimilarity indices about segregation? If one assumes that residential segregation means also socio-spatial isolations of social groups, our results rejects this interpretation. This leads us to conclude that dissimilarity indices may represent a groups' distribution in residential space, relative to the distribution of alternative groups. In contrast we believe that our indices measures individuals tendency to remain isolated from members of alternative social groups while performing their daily life. The model shows us also that segregation should be perceived as a behavioural phenomenon that may divide individuals from the same ethnic groups. Lastly, the results confirm the validity of our multi-layered model for the case of Tel-Aviv-Jaffa. Members of different groups, who perform their daily life in shared coordinates in Cartesian space and in heterogeneous residential spaces, assign clear preferences to intra-ethnic social networks.

\section{References}

Bauman, Z., 1995: Making and Unmaking of Strangers. Thesis Eleven, vol. 43, 1-16.

Ben Rafael, E., 2000: Collective Identity in Israel. In Herzog, H. (Ed.) Society in the Mirror, Ramot, Tel Aviv University: Tel Aviv. 489-514 (Hebrew).

Benenson, I., Omer, I., 2002: Segregation in Space - A Formal Approach and a Case Study. In Schnell, I. and Ostendorf W. (Eds.) Studies in Segregation and Desegregation, Ashgate, Aldershot. P 11-38.

Boal, F. W., 1987: Segregation. In C. Peach (ed), Social Geography, Progress and Prospect, Croom Helm, Beckenham, New York.

Jackson, P. Smith, S., 1984: Exploring Social Geography. Allen and Anwin, London.

Lisak, M., 2000: Are the Tribes of Israel United? Major Cleavages in Israeli Society, in Kop. Y. (Ed.) Pluralism in Israel - From The Melting Pot To Jerusalem Mix, The Center for Policy Studies in Israel: Jerusalem. 27-54 (Hebrew).

Massey, D. and Denton, N., 1988: The Dimensions of Residential Segregation. Social Forces, Vol. 76. 281-315. 
Morgan, B. S., 1983: A Distance-Decay Interaction Index to Measure Residential Segregation. Area, vol. 12, 211-216.

Morrill, R. L., 1991; On the Measure of Geographical Segregation. Geography Research Forum, vol, 11, 25-36.

Newman, D., 2001: From National To Post-National Territorial Identities In Israel-Palestine. Geojournal, 7-23

Peled, Y., 1992: Ethnic Democracy And The Legal Construction Of Citizenship: Arab Citizens Of The Jewish State. American Political Science Review, 86,2, 432-443.

Peled, Y., Shafir, G., 1993: The Roots Of Peace Making: The Dynamics of Citizenship in Israel. International Journal of Middle Eastern Studies, 28, 391-413.

Ram, U., 1999: Between arms and Economy: Israel in the Glocal Era. Israeli Sociology, 2,2. 99-145.

Schnell, I., 2002: Segregation in Everyday Life Spaces: A Conceptual Model. In Schnell, I. and Ostendorf, W. (eds.) Studies in Segregation and Desegregation, Avebury: Aldershot.

Schnell, I., \& Benjamini, Y., 1999: Socio-Spatial Lifestyles and Segregation. Cybergeo.

Schnell, I., Benjamini, Y., 2001: The Socio-Spatial Isolation of Agents in Everyday Life Spaces as an Aspect of Segregation. Annals of the Association of American Geographers, 91, 4. 622-633.

Tukey, J. W., 1977: Exploratory Data Analysi. Addison-Wesley, Massachusetts.

Waldorf, B.S., 1993: Segregation in Urban Space: A New Measurement Approach. Urban Studies, 30, 7, 1170-1192.

Wong, D. W., 1998: Measuring Multiethnic Spatial Segregation. Urban Geography, 19,1, 77-87.

Ya'ar, E., 2001: Trends of Unity and Fragmentation in Israeli Society, Mifne, 33, 3-6 (Hebrew). 